\title{
Heterosynaptic Long-Term Potentiation of Inhibitory Interneurons in the Lateral Amygdala
}

\author{
Elizabeth P. Bauer and Joseph E. LeDoux \\ W. M. Keck Foundation Laboratory of Neurobiology, Center for Neural Science, New York University, New York, New York 10003
}

\begin{abstract}
Long-term potentiation (LTP) of synaptic transmission in the lateral amygdala (LA) is believed to underlie the formation and retention of fear memories. To explore the role of inhibitory transmission in amygdala plasticity, we recorded from LA inhibitory interneurons in vitro before and after tetanization of the thalamo-LA pathway, one of the major inputs to LA involved in fear learning. Tetanization resulted in LTP of the EPSPs elicited in both the tetanized thalamic pathway and the untetanized cortical pathway to LA. This LTP was NMDA-dependent and associated with a decrease in paired-pulse facilitation in both pathways. In LA excitatory cells, LTP of interneurons resulted in an increase in the amplitude of GABAergic IPSPs in both input pathways. Finally, isolated GABAergic IPSPs between inhibitory and excitatory neurons could be potentiated as well. Plasticity of inhibitory transmission within the LA may therefore contribute significantly to LA-mediated functions, such as fear conditioning.
\end{abstract}

Key words: fear conditioning; inhibition; input specific; GABA; LTP; NMDA

\section{Introduction}

Pavlovian auditory fear conditioning, in which a neutral conditioned stimulus (CS) such as a tone is paired with an unconditioned stimulus (US), typically a foot shock, results in longlasting changes in synaptic transmission in the lateral amygdala (LA) (Quirk et al., 1995; McKernan and Shinnick-Gallagher, 1997; Rogan et al., 1997; Collins and Pare, 2000; Repa et al., 2001). One candidate mechanism for these changes is long-term potentiation (LTP) of excitatory cells. LTP can be induced in the major sensory input pathways to LA both in vivo (Rogan and LeDoux, 1995; Doyere et al., 2003) and in vitro (Chapman et al., 1990; Huang and Kandel, 1998; Weisskopf et al., 1999). Moreover, fear conditioning and LTP share similar biochemical mechanisms (Huang and Kandel, 1998; Schafe et al., 2000; Bauer et al., 2002; Rodrigues et al., 2004).

Most studies of LTP in LA have focused on identifying the mechanisms of synaptic plasticity in excitatory principal neurons. However, $\sim 25 \%$ of the neurons in LA are inhibitory interneurons (McDonald and Augustine, 1993). These cells receive input from the auditory thalamus and cortex as well as feedback excitation from LA excitatory cells (Smith et al., 2000; Szinyei et al., 2000; Woodson et al., 2000), and control the activity of LA principal cells (Li et al., 1996; Lang and Pare, 1997, 1998). Furthermore, the ability to induce LTP in excitatory cells in vitro depends on the strength of the local inhibitory network (Marsicano et al., 2002; Shumyatsky et al., 2002). In the hippocampus

Received March 5, 2004; revised Sept. 22, 2004; accepted Sept. 22, 2004.

This work was supported by National Institute of Mental Health Grants R01 MH 46516, R37 MH 38774, and K05 MH 067048 and by National Institutes of Health Predoctoral Grant F31 NS43899. We thank Glenn Schafe and Svetlana Rosis for helpful comments on this manuscript.

Correspondence should be addressed to Elizabeth P. Bauer, Center for Neural Science, New York University, 4 Washington Place, Room 809, New York, NY 10003. E-mail: bauer@cns.nyu.edu.

DOI:10.1523/JNEUROSCI.3567-04.2004

Copyright $\odot 2004$ Society for Neuroscience $\quad$ 0270-6474/04/249507-06\$15.00/0 and cortex, GABAergic inhibitory interneurons can exert a powerful control over the activity of their target cells (for review, see (Freund and Buzsaki, 1996).

A previous study has reported that LTP can be induced in inhibitory neurons in LA by stimulating cortical inputs to LA (Mahanty and Sah, 1998). However, given the prominent role of thalamic inputs to LA in fear conditioning (LeDoux, 2000; Repa et al., 2001), we examined whether LTP can be induced at thalamic inputs to LA interneurons, and, if so, whether this LTP is specific to the stimulated pathway.

\section{Materials and Methods}

Electrophysiological experiments in amygdala slices were conducted as described previously (Weisskopf et al., 1999). All procedures were in accordance with the National Institutes of Health Guide for the Care and Use of Experimental Animals and were approved by the New York University Animal Care and Use Committee.

In brief, male Sprague Dawley rats (3-4 weeks old) were deeply anesthetized with halothane, and the brain was rapidly removed and transferred to ice-cold artificial CSF (ACSF) containing (in mM): $115 \mathrm{NaCl}, 3.3$ $\mathrm{KCl}, 1 \mathrm{MgSO}_{4}, 2 \mathrm{CaCl}_{2}, 25.5 \mathrm{NaHCO}_{3}, 1.2 \mathrm{NaH}_{2} \mathrm{PO}_{4}$, and 25 glucose (equilibrated with $95 \% \mathrm{O}_{2}$ and $5 \% \mathrm{CO}_{2}$ ). Coronal slices (400- $\mu$ m-thick) containing the amygdala were cut and recovered in a holding chamber at $32-34^{\circ} \mathrm{C}$ for $30 \mathrm{~min}$ and were then allowed to return to room temperature for at least another $30 \mathrm{~min}$ before recording. Whole-cell patch recordings were performed under visual guidance. Electrodes were filled with (in $\mathrm{mm}$ ): $130 \mathrm{~K}$-gluconate, 10 phosphocreatine, $2 \mathrm{MgCl}_{2}, 5 \mathrm{KCl}, 10$ HEPES, $4 \mathrm{Mg}$-ATP, and $0.3 \mathrm{Na}_{3}$-GTP, and had resistances of $4-8 \mathrm{M} \Omega$. In some experiments, $10 \mathrm{~mm}$ BAPTA was included in the internal solution, and osmolarity and $\mathrm{pH}$ were readjusted.

Stimuli (150 $\mu$ sec duration) were delivered through bipolar stainless steel electrodes placed in the external capsule, just dorsal to LA, and in the ventral striatum, just medial to LA to stimulate fibers originating in the auditory cortex and thalamus, respectively (Weisskopf et al., 1999). In experiments in which GABA-mediated currents were isolated, an electrode was positioned within the dorsal tip of the LA. For each cell, we 

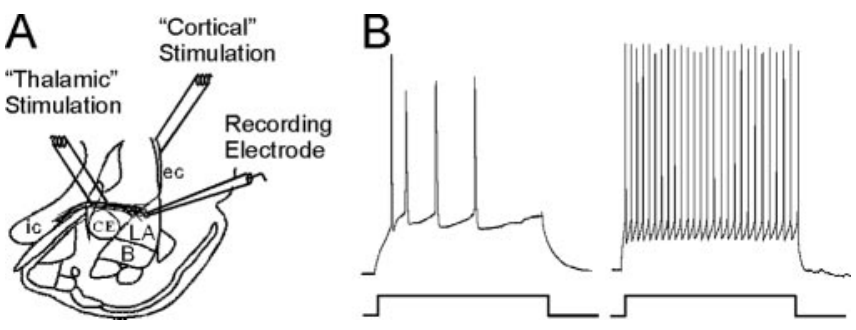

Figure 1. Whole-cell recordings from $L A$ neurons. $A$, Schematic of stimulating and recording electrode placement. $C E$, Central nucleus; B, basal nucleus; ec, external capsule; ic, internal capsule. $B$, Response of an excitatory (left), and inhibitory (right) cell to a positive current injection of $0.15 \mathrm{nA}$.

measured the initial slope of the EPSP during the first 2-3 msec after the onset of the response. Confounds introduced by polysynaptic responses were controlled for by keeping the stimulation intensity at a minimum to prevent polysynaptic responses or spiking, by computing percentage of increase of the initial slope of the EPSP, and by excluding any data that demonstrated a change in EPSP latency after LTP induction.

To measure the amplitude of IPSPs, excitatory cells were held depolarized (by positive current injection). Membrane potential was strictly monitored and did not vary throughout the experiment. For each excitatory neuron in which IPSPs were monitored $(n=32)$, we calculated the mean and SD of the holding membrane potential. The average SD was 0.84 (mean $V_{\mathrm{m}}=-59.32 \mathrm{mV}$ ), and was always $<2 \mathrm{mV}$. There was also no observable up or down drift in the holding potential for each cell throughout the course of the experiment. Therefore any change in IPSP amplitude over the course of the experiment was not attributable to a change in the holding potential of the cell. We also measured the stability of the inhibitory interneurons from which we recorded. The average SD of the resting membrane potential was 1.1 (mean $V_{\mathrm{m}}=-67.3 \mathrm{mV}$ ).

Baseline responses were monitored at $0.05 \mathrm{~Hz}$ in each pathway. After stabilization of baseline responses ( $10-15 \mathrm{~min}$ ), LTP was induced by a 30 $\mathrm{Hz}$ tetanus (100 stimuli, given twice with a $20 \mathrm{sec}$ interval) to one pathway. The stimulation intensity during the tetanus was the same as that used to elicit baseline EPSPs, which was $\sim 50 \%$ of the maximum EPSP response. After LTP induction, test stimuli were presented to each pathway at $0.05 \mathrm{~Hz}$ for a total of $60 \mathrm{~min}$. Drugs used were D-(-)-2-amino-5phosphonopentanoic acid (APV), 6-cyano-7-nitroquinoxaline-2,3dione (CNQX), 1,2-bis(2-aminophenoxy)ethane- $N, N, N^{\prime}, N^{\prime}$-tetraacetic acid (BAPTA), and picrotoxin (Sigma, St. Louis, MO).

For analysis, values were binned into $1 \mathrm{~min}$ intervals and expressed as a percentage of baseline \pm SE. The values recorded during the last $10 \mathrm{~min}$ (minutes 50-60) were averaged into a single score for each cell and were compared with preinduction values ( $5 \mathrm{~min}$ before induction) to compute the amount of potentiation. Significance relative to baseline was tested with a paired Student's $t$ test. Differences were considered significant if $p<0.05$.

\section{Results}

Physiological identification of inhibitory interneurons in LA All recorded LA neurons were identified as either excitatory principal cells or inhibitory interneurons, based on intrinsic membrane properties and firing patterns (Washburn and Moises, 1992a,b; Rainnie et al., 1993). Excitatory neurons had broad action potentials and showed spike frequency adaptation. Inhibitory interneurons showed high-frequency firing of action potentials with a distinct afterhyperpolarization after each spike, and no spike frequency adaptation (Fig. $1 B$ ). For inhibitory cells, the average resting membrane potential, input resistance, and action potential duration at half-maximal amplitude were $-67.3 \pm 1.4$ $\mathrm{mV}, 195 \pm 15.3 \mathrm{M} \Omega$, and $0.91 \pm 0.06 \mathrm{msec}$, respectively, in agreement with previous characterizations (Washburn and Moises, 1992b; Rainnie et al., 1993).
Tetanization of afferents to LA induces LTP of EPSPs in inhibitory cells

Monosynaptic EPSP responses were evoked in inhibitory interneurons by stimulating fibers originating in the auditory thalamus and cortex (Weisskopf et al., 1999) (Fig. 1A). Baseline responses were monitored in each pathway at $0.05 \mathrm{~Hz}$ for $10-15$ min to achieve a stable baseline. A $30 \mathrm{~Hz}$ tetanus (100 stimuli given twice) was delivered to the thalamic fibers, and responses elicited by test pulses in the two pathways were monitored for an additional hour. Inhibitory neurons showed occasional failures to respond to afferent stimulation. These trials were excluded from analysis.

Tetanization of thalamic afferents to LA interneurons $(n=$ 12) resulted in potentiation of EPSP responses in all neurons in both the thalamo-LA pathway and the untetanized cortico-LA pathway (Fig. $2 A$ ). In the thalamo-LA pathway, the EPSP slope was potentiated to $129 \pm 9 \%$ of baseline $\left(t_{(11)}=2.70 ; p<0.05\right)$. Stable monosynaptic cortico-LA responses were evoked in 11 of these 12 cells. These cortical EPSPs were potentiated to $140 \pm$ $11 \%$ of baseline $\left(t_{(10)}=3.44 ; p<0.05\right)$ after tetanization of the thalamic pathway.

As a first step in localizing the expression of LTP in inhibitory neurons, we examined the effects of LTP on paired-pulse facilitation (PPF). PPF is a presynaptic phenomenon; a decrease in PPF after LTP induction can signify an increase in presynaptic transmitter release, and thus a presynaptic site of LTP expression. We analyzed PPF in the thalamo-LA pathway ( $n=5$ cells $)$ and in the cortico-LA pathway ( $n=4$ cells) before, $30 \mathrm{~min}$, and $60 \mathrm{~min}$ after LTP induction (Fig. $1 \mathrm{~B}$ ). PPF was measured by giving pairs of pulses separated by $50 \mathrm{msec}$ and computing the percentage increase in EPSP slope in the second response. During baseline stimulation, before tetanization, the second EPSP was facilitated to $213 \pm 50 \%$ of the first response in the thalamic pathway and $246 \pm 67 \%$ of the first response in the cortical pathway. Thirty minutes after tetanization of thalamic inputs, PPF was significantly reduced to $124 \pm 23 \%$ in the thalamic pathway $\left(t_{(4)}=2.87\right.$; $p<0.05)$ and $153 \pm 46 \%$ in the cortical pathway $\left(t_{(3)}=3.23 ; p<\right.$ $0.05)$. Sixty minutes after tetanization, PPF was $138 \pm 32 \%$ in the thalamic pathway $\left(t_{(4)}=2.13 ; p<0.05\right)$ and $168 \pm 47 \%$ in the cortical pathway $\left(t_{(3)}=3.23 ; p<0.05\right)$. In sum, LTP of inhibitory neurons was associated with a decrease in PPF in both the tetanized (thalamic) and untetanized (cortical) pathways, suggesting that LTP of inhibitory neurons is expressed through an increase in presynaptic neurotransmitter release or, alternatively, by the activation of previously silent synapses (Malinow and Malenka, 2002).

In LA excitatory neurons, an NMDA-dependent LTP can be induced at both cortical and thalamic input synapses (Huang and Kandel, 1998; Bauer et al., 2002). Because LA interneurons also possess NMDA receptors (Szinyei et al., 2003), we examined the effects of the NMDA receptor antagonist APV $(50 \mu \mathrm{M})$ on the induction of LTP in inhibitory neurons $(n=3)$ (Fig. $1 C)$. During the last $10 \mathrm{~min}$ of recording (minutes 35-45), neither thalamo-LA EPSPs $(105 \pm 3.0 \%)$ nor cortico-LA EPSPs $(91 \pm$ $16 \%$ ) were significantly different from baseline $(p>0.05)$. Thus, LTP induction in LA inhibitory interneurons depends on NMDA receptors.

\section{Thalamic and cortical inputs do not overlap}

Previous studies have demonstrated that there is no overlap of cortical and thalamic afferents to LA excitatory or inhibitory neurons (Szinyei et al., 2000; Tsvetkov et al., 2004). To verify this, we used paired-pulse and primed-pulse stimulation of inhibitory 
A Thalamo-LA EPSPs
(tetanized)
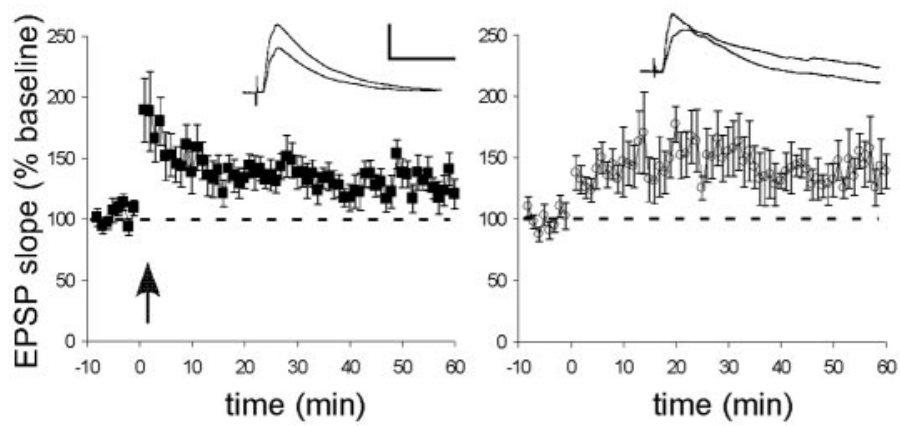

Cortico-LA EPSPs (untetanized)

B Paired-pulse facilitation

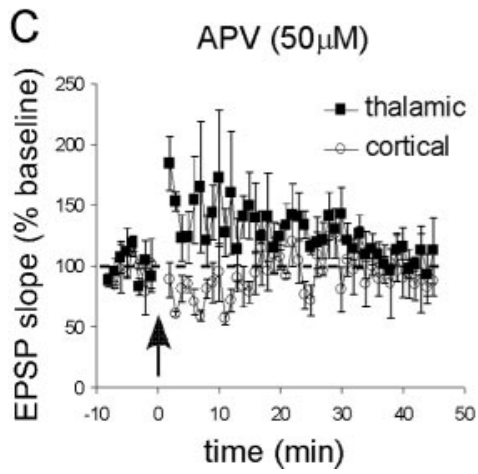

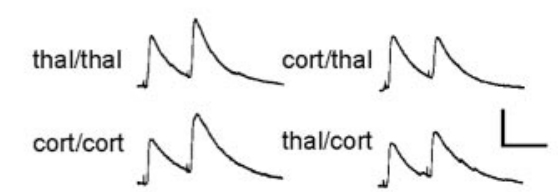

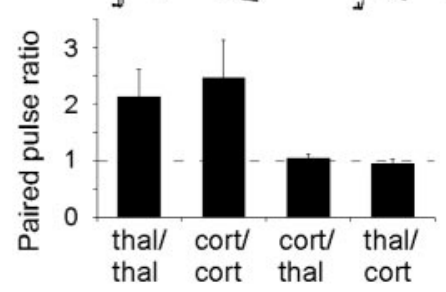

Figure 2. Heterosynaptic LTP of inhibitory neurons. $A$, Mean \pm SE percentage of EPSP slope relative to baseline in response to thalamic (left) or cortical (right) afferent stimulation. A tetanus was given to the thalamic pathway at time 0 . Traces (averages of 5 responses) from individual experiments before and after tetanus are shown in the insets. Calibration: $5 \mathrm{mV}, 40 \mathrm{msec}$. B, PPF in inhibitory neurons in the thalamic (top) and cortical (bottom) input pathways before (Pre), $30 \mathrm{~min}$, and $60 \mathrm{~min}$ after LTP induction (with a tetanus given to the thalamic pathway). PPF was examined with a 50 msec interpulse interval and is measured as the slope of the second EPSP as a percentage of the slope of the first EPSP. C, Mean \pm SE percentage of EPSP slope relative to baseline in response to thalamic (filled squares) or cortical (open circles) afferent stimulation in the presence of $50 \mu \mathrm{m}$ APV with a tetanus given to the thalamic pathway at time $0 . D$, Thalamic and cortical inputs to $L A$ do not show cross-facilitation. Paired-pulse ratios were calculated by dividing the second EPSP response by the first response obtained from the corresponding primed-pulse sequence. Calibration: $4 \mathrm{mV}, 50 \mathrm{msec}$.

neurons to test for cross-facilitation (Fig. 2D). Paired-pulse facilitation was evoked with a $50 \mathrm{msec}$ stimulus interval and was assessed by dividing the slope of the second response by the slope of the first. Both thalamic and cortical inputs showed substantial facilitation when either was stimulated with paired stimuli. Thalamic-thalamic paired pulse ratio was $2.13 \pm 0.5$; cortical-cortical paired pulse ratio was $2.46 \pm 0.67$. Primed-pulse facilitation was calculated by dividing the slope of the second response by the slope of the first obtained from the corresponding primed-pulse sequence. Thalamic-cortical primed pulse ratio was $0.95 \pm 0.08$; and cortical-thalamic primed pulse ratio was $1.04 \pm 0.08(n=4)$. Thus, stimulation of the thalamic pathway with a single stimulus had no effect on the response elicited by cortical stimulation after a $50 \mathrm{msec}$ delay, and vice versa. These data demonstrate that the two inputs do not overlap and function independently.

\section{Tetanization of afferents to LA induces LTP of IPSPs in excitatory cells}

LA interneurons are GABAergic (McDonald and Augustine, 1993) and stimulation of thalamic or cortical afferents produces an IPSP in excitatory cells mediated by $\mathrm{GABA}_{\mathrm{A}}$ and $\mathrm{GABA}_{\mathrm{B}}$ receptors (Rainnie et al., 1991; Washburn and Moises, 1992b; Li et al., 1996). How, then, does heterosynaptic potentiation of GABAergic interneurons affect the activity of LA excitatory cells?
To answer this question, we recorded from physiologically identified principal excitatory neurons and induced LTP as above.

Tetanization of thalamic afferents potentiated thalamo-LA EPSPs in principal cells and potentiated IPSPs in both the thalamic and cortical input pathways to principal cells (Fig. 3A). At minutes 5060 , thalamo-LA EPSPs were potentiated to $134 \pm 11 \%$ of baseline $\left(n=11 ; t_{(10)}=\right.$ 2.65; $p<0.05$ ), whereas cortico-LA EPSPs showed no change: $106 \pm 9.1 \%,(n=8$; $p>0.05)$. The IPSP component of the response was potentiated in the thalamo-LA pathway to $151 \pm 7.8 \%$ of baseline $(n=$ $\left.16 ; t_{(15)}=6.41 ; p<0.01\right)$ and in the cortico-LA pathway to $183 \pm 9.5 \%(n=$ $\left.14 ; t_{(13)}=8.76 ; p<0.01\right)$.

To determine whether the lack of input specificity of IPSP LTP of excitatory neurons depended on which pathway was tetanized, we reversed the above experiment by giving the tetanus to the cortical afferents to LA and observed a similar pattern of results (Fig. 3B). The cortico-LA EPSPs of principal neurons were potentiated to $126 \pm 10 \%$ of baseline at minutes $50-60$ $\left(n=9 ; t_{(8)}=2.39 ; p<0.05\right)$, but the thalamo-LA EPSPs showed no change: $93.7 \pm 6.4 \%$ of baseline $(n=8 ; p>0.05)$. The IPSP amplitude was potentiated in the cortico-LA pathway to $159 \pm 9.8 \%(n=9$; $\left.t_{(8)}=5.24 ; p<0.01\right)$ and in the thalamo-LA pathway to $151 \pm 13.9 \%(n=$ $\left.8 ; t_{(7)}=3.46 ; p<0.05\right)$. In sum, EPSPs were potentiated in the tetanized pathway only, in agreement with previous studies showing that LTP of excitatory transmission in the LA is synapse-specific (Weisskopf et al., 1999). However, the fact that IPSPs were potentiated in both pathways, regardless of which pathway received the tetanus, suggests that LTP of inhibitory transmission to principal cells is not restricted to the tetanized path.

As further support for the claim that LTP of principal excitatory neurons is synapse-specific, whereas LTP of inhibitory interneurons is not, we analyzed PPF in a separate set of excitatory neurons after LTP induction to see if a reduction in PPF was restricted to the tetanized pathway ( $n=8$; data not shown). Picrotoxin $(75 \mu \mathrm{M})$ was included in the ACSF bath to inhibit GABAergic transmission. Sixty minutes after a tetanus to the thalamic input fibers, PPF in that pathway was significantly reduced from $137 \pm 12 \%$ to $101 \pm 7.1 \%\left(t_{(7)}=3.37 ; p<0.05\right)$. PPF in the untetanized cortical pathway, however, was not significantly reduced from $129 \pm 15 \%$ to $119 \pm 12 \%(p>0.05)$. These data suggest that decreases in PPF are associated with LTP and are input-specific in excitatory neurons, but lack input specificity in interneurons.

\section{LTP of GABAergic synapses between inhibitory and excitatory neurons}

The above data suggest that LTP of glutamatergic inputs to interneurons produces potentiation of the disynaptic GABAergic 
IPSPs recorded in LA excitatory neurons. But changes in the strength of the GABAergic synapses themselves between inhibitory and excitatory cells may also contribute to LTP of IPSPs (Fig. 4A). Although LTP of isolated GABAergic synapses has been described throughout the brain (Gaiarsa et al., 2002), it has not been reported in LA. We therefore asked if these synapses are capable of being potentiated. First, we determined the effect of loading the postsynaptic excitatory cell with BAPTA, a calcium chelator $(n=7)$ (Fig. $4 B)$. If BAPTA reduces IPSP LTP, this would indicate that potentiation of GABAergic synapses contributes to IPSP LTP and is calcium-dependent. Alternatively, if BAPTA does not affect IPSP LTP, this would suggest that IPSP LTP can be entirely accounted for by potentiation of inputs to inhibitory cells.

Including BAPTA in the recording pipette to chelate internal calcium in excitatory neurons significantly reduced LTP of IPSPs in both pathways in response to thalamic tetanization. At minutes 50-60, thalamo-LA IPSPs were $121 \pm 9.5 \%$ of baseline, which was significantly lower than controls $\left(t_{(21)}=2.25 ; p<0.05\right)$. Cortico-LA IPSPs were $123 \pm 9.5 \%$ of baseline, which was also significantly different from controls $\left(t_{(19)}=3.93 ; p<\right.$ $0.05)$, indicating that chelating internal calcium in excitatory cells reduces LTP of IPSPs. This suggests that LTP of GABAergic synapses between inhibitory and excitatory neurons contributes to LTP of IPSPs in excitatory LA cells (Fig. 4A).

We next directly tested whether GABAergic synapses are capable of expressing LTP. By placing one set of stimulating electrodes within the LA to directly stimulate inhibitory neurons, and including $10 \mu \mathrm{M}$ CNQX and $50 \mu \mathrm{M}$ APV in the superfusing ACSF to block glutamatergic transmission, we were able to isolate monosynaptic IPSPs $(n=5)$ (Fig. $4 C$ ). At 50-60 min after a tetanus, IPSPs were potentiated to $196 \pm 17 \%$ of baseline $\left(t_{(4)}=\right.$ 5.49; $p<0.05)$.

Last, we examined the effect of LTP on paired-pulse facilitation at isolated GABAergic synapses (Fig. 4D). In agreement with previous findings (Szinyei et al., 2000), paired-pulse stimulation with a $50 \mathrm{msec}$ interstimulus interval resulted in paired-pulse depression (PPD) of the second IPSP. Before tetanization, the second IPSP was depressed to $64 \pm 6.2 \%$ of the amplitude of the first response, whereas at $30 \mathrm{~min}$ it was $62 \pm 11 \%$ and at $60 \mathrm{~min}$ $58 \pm 4.0 \%$. At $30 \mathrm{~min}$, there was no significant change in PPD as revealed by $\operatorname{ANOVA}\left(F_{(1,8)}=0.02 ; p=0.9\right)$. At $60 \mathrm{~min}$ after tetanus, the amount of PPD was still not significantly different from pretetanus $\left(F_{(1,8)}=0.06 ; p=0.82\right)$. These data suggest that plasticity of isolated GABAergic IPSPs is expressed in the postsynaptic excitatory neuron. Collectively, these results suggest that GABAergic synapses in the LA are capable of long-lasting potentiation and contribute to increases in IPSPs in excitatory neurons after a tetanus.

\section{Discussion}

During auditory fear conditioning, CS signals from the auditory thalamus and auditory cortex converge in the LA (Romanski et al., 1993; LeDoux, 2000) and are potentiated (Quirk et al., 1995; Rogan et al., 1997; Collins and Pare, 2000; Goosens et al., 2003). In the present experiments, we examined LTP at thalamic input synapses to LA inhibitory cells. The LTP was heterosynaptic: both tetanized and untetanized inputs to interneurons were strengthened, and this heterosynaptic effect occurred regardless of whether the thalamic or cortical input was tetanized. This LTP was blocked by APV, and was thus dependent on NMDA receptors. This LTP was also associated with a decrease in paired-pulse facilitation in both input pathways, suggesting a possible role for presynaptic plasticity. Furthermore, isolated GABAergic synapses between inhibitory and excitatory neurons were also capable of LTP. The net result of this plasticity was potentiation of GABAergic IPSPs in excitatory cells in both the tetanized and untetanized input pathways.

\section{Heterosynaptic LTP of interneurons}

LA interneurons receive direct input from thalamic and cortical areas (Szinyei et al., 2000; Woodson et al., 2000), as well as projections from excitatory neurons within the LA (Smith et al., 2000). Although plasticity of these intrinsic excitatory inputs could contribute to LTP of IPSPs in excitatory neurons, it cannot fully account for the LTP of interneurons. The fact that LTP of interneurons is heterosynaptic indicates that it cannot result 
A
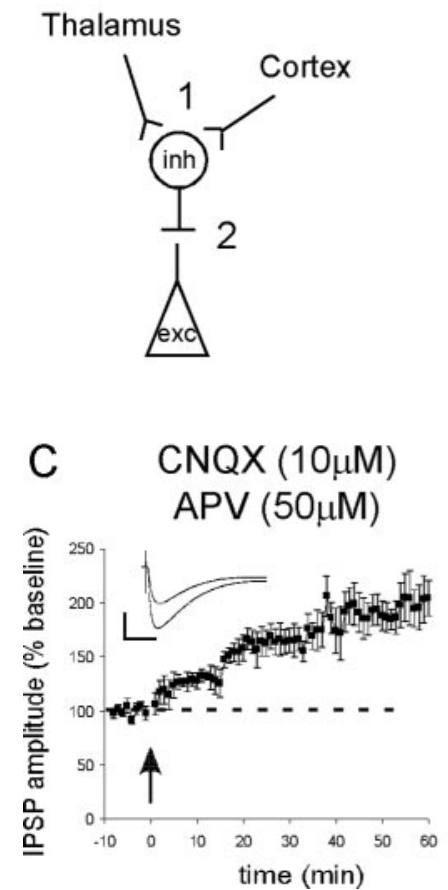

Figure 4. LTP of GABAergic synapses. A, Diagram of the circuitry within the LA. Potentiation of IPSPs in excitatory neurons (exc) can reflect changes at inputs to inhibitory cells (inh, 1) and/or changes of GABAergic synapses between inhibitory and excitatory neurons (2). B, Loading excitatory cells with the calcium chelator BAPTA $(10 \mathrm{~mm})$ reduced IPSP LTP. Mean \pm SE percentage of IPSP maximum amplitude in excitatory cells in response to thalamic (filled squares) or cortical (open circles) input stimulation. A tetanus was given to the thalamic pathway at time 0 . Traces from individual experiments showing thalamo-LA (left) and cortico-LA (right) responses before and $60 \mathrm{~min}$ after tetanus are shown above. Calibration: $5 \mathrm{mV}, 50 \mathrm{msec}$. C, GABAergic IPSPs between inhibitory and excitatory neurons were isolated with CNQX (10 $\mu \mathrm{M})$ and APV $(50 \mu \mathrm{M})$. Mean \pm SE percentage of IPSP maximum amplitude in response to stimulation from an electrode placed within the dorsal tip of the LA. A tetanus was given at time 0 . Traces from an individual experiment before and $60 \mathrm{~min}$ after tetanus are shown in the inset. Calibration: $3 \mathrm{mV}, 50 \mathrm{msec}$. D, PPD of isolated GABAergic IPSPs before (Pre), 30, and $60 \mathrm{~min}$ after LTP induction. PPD was examined with a 50 msec interpulse interval and is measured as the amplitude of the second IPSP as a percentage of the amplitude of the first IPSP.

from the homosynaptic LTP of excitatory projection neurons. What, then, explains the spread of LTP to untetanized inputs on inhibitory cells in LA? Several possible factors include the lack of spines in inhibitory interneurons (Washburn and Moises, 1992a; Rainnie et al., 1993), or the distribution and/or activation patterns of postsynaptic receptors, second messenger systems, and calcium-binding proteins (Nishiyama et al., 2000).

Although potentiation of tetanized inputs was immediate, LTP of the other inputs was slower, suggesting that the underlying mechanisms of the two forms of LTP may differ. This slow time course could be caused by the diffusion of second messengers within the postsynaptic cell (Nishiyama et al., 2000) or retrograde messengers to presynaptic terminals (Marsicano et al., 2002).

LTP of LA interneurons is dependent on postsynaptic calcium (Mahanty and Sah, 1998). Our results suggest that this calcium enters through NMDA receptors. NMDA receptors have also been implicated in LTP of LA excitatory cells (Huang and Kandel, 1998; Bauer et al., 2002), suggesting that plasticity of excitatory and inhibitory neurons in the LA may have other pharmacological mechanisms in common as well. In the LA, AMPA receptors on inhibitory neurons lack the GluR2 subunit, making them calcium-permeable (Mahanty and Sah, 1998). Interestingly, although calcium could still enter the postsynaptic cell through these AMPA receptors during application of APV, because blockade of NMDA receptors with APV leaves these AMPA receptors intact, it was apparently not sufficient to produce LTP. It should be noted that several studies have shown that NMDA receptors contribute to basal synaptic transmission in LA interneurons ( $\mathrm{Sz}$ inyei et al., 2003), as well as in excitatory cells in LA (Li et al., 1995; Weisskopf and LeDoux, 1999; Bauer et al., 2002). The reduction in LTP we see in the presence of APV could therefore also be explained in terms of a reduction in excitatory transmission at afferent synapses to interneurons.

It has been recently reported (Humeau et al., 2003) that activation of presynaptic NMDA receptors on cortical axons by thalamic inputs can induce a presynaptically expressed LTP of cortical inputs onto excitatory neurons. If cortical inputs to interneurons also express NMDA receptors, this mechanism could, at least in part, explain the LTP of cortical inputs to interneurons described here. Indeed, the decrease in PPF associated with LTP, and the involvement of NMDA receptors suggests that this type of presynaptic plasticity could contribute to LTP. Additional experiments will be necessary to evaluate this possibility.

\section{LTP of GABAergic synapses}

These results also reveal that GABAergic synapses onto excitatory neurons are capable of LTP. This is the first demonstration of this type of plasticity in LA, although a previous study has shown that isolated IPSPs are capable of an endocannabinoid-dependent LTD (Marsicano et al., 2002). Here, chelating calcium with BAPTA in the postsynaptic excitatory cell reduced LTP of IPSPs, and isolated IPSPs showed no change in PPD after tetanization, suggesting that LTP of GABAergic synapses onto excitatory neurons is expressed postsynaptically.

\section{Implications for information processing in LA}

Inhibition exerts a powerful control over the activity of projecting LA principal cells (Lang and Pare, 1997, 1998). Interneurons have a lower spike threshold and show no spike frequency adaptation, so strong stimulation of afferent inputs to LA produces a predominantly hyperpolarizing response in excitatory cells (Rainnie et al., 1991; Lang and Pare, 1997). Moreover, IPSPs truncate evoked and spontaneous EPSPs in excitatory neurons. This suggests that IPSP potentiation might alter the input-output functions of LA principal cells (Lang and Pare, 1997; Gaiarsa et al., 2002).

Our data have important implications for the processing of conditioned stimuli during fear conditioning. Because LTP of inhibitory interneurons is not input-specific, fear conditioning might lead to potentiation of much of the inhibitory network within the LA. By increasing inhibition on inputs not actively involved in CS-US integration, plasticity of interneurons may therefore serve to reduce activity and plasticity at those synapses and thus increase the signal-to-noise ratio of CS processing.

Inhibitory transmission in LA may also play a role in the extinction of fear memories. The medial prefrontal cortex (mPFC) is thought to inhibit amygdala output during fear extinction (Morgan et al., 1993; Milad and Quirk, 2002; Sotres-Bayon et al., 2004). One theory posits that the mPFC exerts its inhibitory control via projections to interneurons in the LA (Rosenkranz et al., 2003). If this projection is strengthened during extinction through potentiation of interneurons, this would decrease the activity of LA projection neurons. Indeed, modulation of the inhibitory network in the amygdala affects both fear learning and extinction (Marsicano et al., 2002; Shumyatsky et al., 2002). The 
involvement of LA interneurons in fear extinction is controversial, however (Quirk et al., 2003; Pare et al., 2004).

In conclusion, inhibitory interneurons in the LA are capable of long-lasting potentiation that is not synapse-specific. This LTP, together with LTP of GABAergic synapses between inhibitory and excitatory neurons, contributes to the strengthening of the inhibitory network in the LA. Further experiments will be needed to see how this heterosynaptic LTP of interneurons contributes to synaptic plasticity during fear learning. Characterization of LA neuronal activity is necessary for understanding the basis of auditory conditioned fear responses and more generally of emotional expression.

\section{References}

Bauer EP, Schafe GE, LeDoux JE (2002) NMDA receptors and L-type voltage-gated calcium channels contribute to long-term potentiation and different components of fear memory formation in the lateral amygdala. J Neurosci 22:5239-5249.

Chapman PF, Kairiss EW, Keenan CL, Brown TH (1990) Long-term synaptic potentiation in the amygdala. Synapse 6:271-278.

Collins DR, Pare D (2000) Differential fear conditioning induces reciprocal changes in the sensory responses of lateral amygdala neurons to the CS(+) and CS(-). Learn Mem 7:97-103.

Doyere V, Schafe GE, Sigurdsson T, LeDoux JE (2003) Long-term potentiation in freely moving rats reveals asymmetries in thalamic and cortical inputs to the lateral amygdala. Eur J Neurosci 17:2703-2715.

Freund TF, Buzsaki G (1996) Interneurons of the hippocampus. Hippocampus 6:347-470.

Gaiarsa JL, Caillard O, Ben-Ari Y (2002) Long-term plasticity at GABAergic and glycinergic synapses: mechanisms and functional significance. Trends Neurosci 25:564-570.

Goosens KA, Hobin JA, Maren S (2003) Auditory-evoked spike firing in the lateral amygdala and pavlovian fear conditioning: mnemonic code or fear bias? Neuron 40:1013-1022.

Huang YY, Kandel ER (1998) Postsynaptic induction and PKA-dependent expression of LTP in the lateral amygdala. Neuron 21:169-178.

Humeau Y, Shaban H, Bissiere S, Luthi A (2003) Presynaptic induction of heterosynaptic associative plasticity in the mammalian brain. Nature 426:841-845

Lang EJ, Pare D (1997) Similar inhibitory processes dominate the responses of cat lateral amygdaloid projection neurons to their various afferents. J Neurophysiol 77:341-352.

Lang EJ, Pare D (1998) Synaptic responsiveness of interneurons of the cat lateral amygdaloid nucleus. Neuroscience 83:877-889.

LeDoux JE (2000) Emotion circuits in the brain. Annu Rev Neurosci 23:155-184.

Li XF, Phillips R, LeDoux JE (1995) NMDA and non-NMDA receptors contribute to synaptic transmission between the medial geniculate body and the lateral nucleus of the amygdala. Exp Brain Res 105:87-100.

Li XF, Armony JL, LeDoux JE (1996) GABAA and GABAB receptors differentially regulate synaptic transmission in the auditory thalamo-amygdala pathway: an in vivo microiontophoretic study and a model. Synapse 24:115-124.

Mahanty NK, Sah P (1998) Calcium-permeable AMPA receptors mediate long-term potentiation in interneurons in the amygdala. Nature 394:683-687.

Malinow R, Malenka RC (2002) AMPA receptor trafficking and synaptic plasticity. Annu Rev Neurosci 25:103-126.

Marsicano G, Wotjak CT, Azad SC, Bisogno T, Rammes G, Cascio MG, Hermann H, Tang J, Hofmann C, Zieglgansberger W, Di Marzo V, Lutz B (2002) The endogenous cannabinoid system controls extinction of aversive memories. Nature 418:530-534.

McDonald AJ, Augustine JR (1993) Localization of GABA-like immunoreactivity in the monkey amygdala. Neuroscience 52:281-294.

McKernan MG, Shinnick-Gallagher P (1997) Fear conditioning induces a lasting potentiation of synaptic currents in vitro. Nature 390:607-611.

Milad MR, Quirk GJ (2002) Neurons in medial prefrontal cortex signal memory for fear extinction. Nature 420:70-74.

Morgan MA, Romanski LM, LeDoux JE (1993) Extinction of emotional learning: contribution of medial prefrontal cortex. Neurosci Lett 163:109-113.

Nishiyama M, Hong K, Mikoshiba K, Poo MM, Kato K (2000) Calcium stores regulate the polarity and input specificity of synaptic modification. Nature 408:584-588.

Pare D, Quirk GJ, Ledoux JE (2004) New vistas on amygdala networks in conditioned fear. J Neurophysiol 92:1-9.

Quirk GJ, Repa C, LeDoux JE (1995) Fear conditioning enhances shortlatency auditory responses of lateral amygdala neurons: parallel recordings in the freely behaving rat. Neuron 15:1029-1039.

Quirk GJ, Likhtik E, Pelletier JG, Pare D (2003) Stimulation of medial prefrontal cortex decreases the responsiveness of central amygdala output neurons. J Neurosci 23:8800-8807.

Rainnie DG, Asprodini EK, Shinnick-Gallagher P (1991) Inhibitory transmission in the basolateral amygdala. J Neurophysiol 66:999-1009.

Rainnie DG, Asprodini EK, Shinnick-Gallagher P (1993) Intracellular recordings from morphologically identified neurons of the basolateral amygdala. J Neurophysiol 69:1350-1362.

Repa JC, Muller J, Apergis J, Desrochers TM, Zhou Y, LeDoux JE (2001) Two different lateral amygdala cell populations contribute to the initiation and storage of memory. Nat Neurosci 4:724-731.

Rodrigues SM, Schafe GE, LeDoux JE (2004) Molecular mechanisms underlying emotional learning and memory in the lateral amygdala. Neuron 44:75-91.

Rogan MT, LeDoux JE (1995) LTP is accompanied by commensurate enhancement of auditory-evoked responses in a fear conditioning circuit. Neuron 15:127-136.

Rogan MT, Staubli UV, LeDoux JE (1997) Fear conditioning induces associative long-term potentiation in the amygdala. Nature 390:604-607.

Romanski LM, Clugnet MC, Bordi F, LeDoux JE (1993) Somatosensory and auditory convergence in the lateral nucleus of the amygdala. Behav Neurosci 107:444-450.

Rosenkranz JA, Moore H, Grace AA (2003) The prefrontal cortex regulates lateral amygdala neuronal plasticity and responses to previously conditioned stimuli. J Neurosci 23:11054-11064.

Schafe GE, Atkins CM, Swank MW, Bauer EP, Sweatt JD, LeDoux JE (2000) Activation of ERK/MAP kinase in the amygdala is required for memory consolidation of pavlovian fear conditioning. J Neurosci 20:8177-8187.

Shumyatsky GP, Tsvetkov E, Malleret G, Vronskaya S, Hatton M, Hampton L, Battey JF, Dulac C, Kandel ER, Bolshakov VY (2002) Identification of a signaling network in lateral nucleus of amygdala important for inhibiting memory specifically related to learned fear. Cell 111:905-918.

Smith Y, Pare JF, Pare D (2000) Differential innervation of parvalbuminimmunoreactive interneurons of the basolateral amygdaloid complex by cortical and intrinsic inputs. J Comp Neurol 416:496-508.

Sotres-Bayon F, Bush DEA, LeDoux JE (2004) Emotional perseveration: an update on prefrontal-amygdala interactions in fear extinction. Learn Mem 11:525-535.

Szinyei C, Heinbockel T, Montagne J, Pape HC (2000) Putative cortical and thalamic inputs elicit convergent excitation in a population of GABAergic interneurons of the lateral amygdala. J Neurosci 20:8909-8915.

Szinyei C, Stork O, Pape HC (2003) Contribution of NR2B subunits to synaptic transmission in amygdaloid interneurons. J Neurosci 23:2549-2556.

Tsvetkov E, Shin RM, Bolshakov VY (2004) Glutamate uptake determines pathway specificity of long-term potentiation in the neural circuitry of fear conditioning. Neuron 41:139-151.

Washburn MS, Moises HC (1992a) Electrophysiological and morphological properties of rat basolateral amygdaloid neurons in vitro. J Neurosci 12:4066-4079.

Washburn MS, Moises HC (1992b) Inhibitory responses of rat basolateral amygdaloid neurons recorded in vitro. Neuroscience 50:811-830.

Weisskopf MG, LeDoux JE (1999) Distinct populations of NMDA receptors at subcortical and cortical inputs to principal cells of the lateral amygdala. J Neurophysiol 81:930-934.

Weisskopf MG, Bauer EP, LeDoux JE (1999) L-type voltage-gated calcium channels mediate NMDA-independent associative long-term potentiation at thalamic input synapses to the amygdala. J Neurosci 19:10512-10519.

Woodson W, Farb CR, Ledoux JE (2000) Afferents from the auditory thalamus synapse on inhibitory interneurons in the lateral nucleus of the amygdala. Synapse 38:124-137. 